\title{
Rare Presentation of Limb-Body Wall Complex in a Neonate: Case Report and Review of Literature
}

\author{
Omoloro Adeleke, $\mathrm{MD}^{1}$ Farrukh Gill, $\mathrm{MD}^{2}$ Ramesh Krishnan, $\mathrm{MD}^{1 \odot}$ \\ ${ }^{1}$ Department of Pediatrics, The University of Tennessee Health \\ Science Center, Memphis, Tennessee \\ 2 Department of Pathology, The University of Tennessee Health \\ Science Center, Memphis, Tennessee \\ Address for correspondence Omoloro Adeleke, MD, Department of \\ Neonatal-Perinatal Medicine, The University of Tennessee Health \\ Science, 853 Jefferson Avenue, \#2, Memphis, TN 38103 \\ (e-mail: oadeleke@uthsc.edu).
}

AJP Rep 2022;12:e108-e112.

\author{
Abstract \\ Keywords \\ - limb-body wall \\ complex \\ - body stalk syndrome \\ - limb defects \\ - thoracoschisis \\ - abdominoschisis \\ - omphalocele \\ - gastroschisis
}

The limb-body wall complex (LBWC) aka body stalk syndrome is an uncommon congenital disorder characterized by severe malformations of limb, thorax, and abdomen, characterized by the presence of thoracoschisis, abdominoschisis, limb defects, and exencephaly. This condition is extremely rare with an incidence of 1 per 14,000 and 1 per 31,000 pregnancies in large epidemiologic studies. Majority of these malformed fetuses end up with spontaneous abortions. We present this rare case with occurrence in a preterm infant of 35 weeks' gestation. Our report highlights majority of the clinical presentations as reported in previous literature, but the significant pathological findings of absent genitalia and malformed genitourinary as well as anorectal malformations make this case presentation an even more rare occurrence. Infant karyotyping was normal male and there is no specific underlying genetic correlation in this condition which has a fatal prognosis.
A neonate weighing $1,700 \mathrm{~g}$ was delivered by spontaneous vaginal delivery at $35^{2 / 7}$ weeks of gestation by a 17 -year-old G2 P0010 mother. Mother had a previous spontaneous miscarriage at 8 weeks' gestation (blighted ovum). There was no family history of congenital malformations or consanguinity. There was no history of drug intake other than hematinic during this pregnancy. The mother's prenatal test results were within normal range and had regular prenatal visits with her obstetrician and high-risk maternal-fetal medicine due to prenatal ultrasound findings of multiple congenital anomalies in her unborn child. Her initial ultrasound study showed findings of club feet, gastroschisis, and pulmonary hypoplasia in her unborn fetus which subsequently was confirmed to be a rare case of limb-body wall complex (LBWC) on detailed ultrasound scans by maternal-fetal medicine experts. The neonatal team was consulted and the medical teams after discussion decided to offer comfort care as an option to the family given the fatal prognosis with this condition based on existing literature evidence. Mother decided on comfort care measures only. She was admitted to the hospital at 35 weeks with onset of spontaneous labor and neonate was delivered following 32 hours of preterm premature rupture of membranes. At delivery, neonate was limp, apneic with no cry. Neonate was brought to radiant warmer dried, and airway suctioned and cleared. Infant's heart rate was less than 60 with associated LBWC findings (-Figs. 1-5) as noted on the prenatal ultrasound imaging. As per mother's received

August 16, 2021

accepted after revision

December 20, 2021
DOI https://doi.org/ 10.1055/a-1740-5463. ISSN 2157-6998.

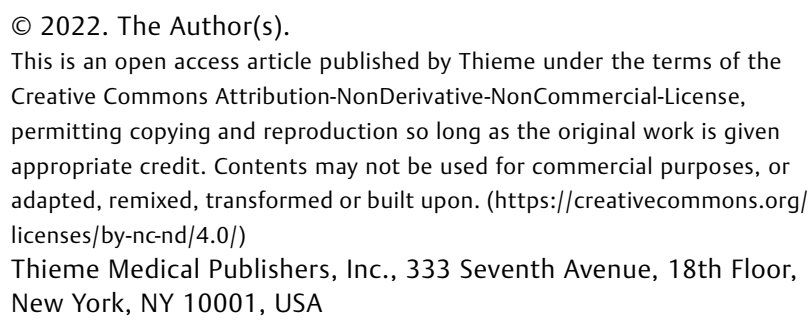




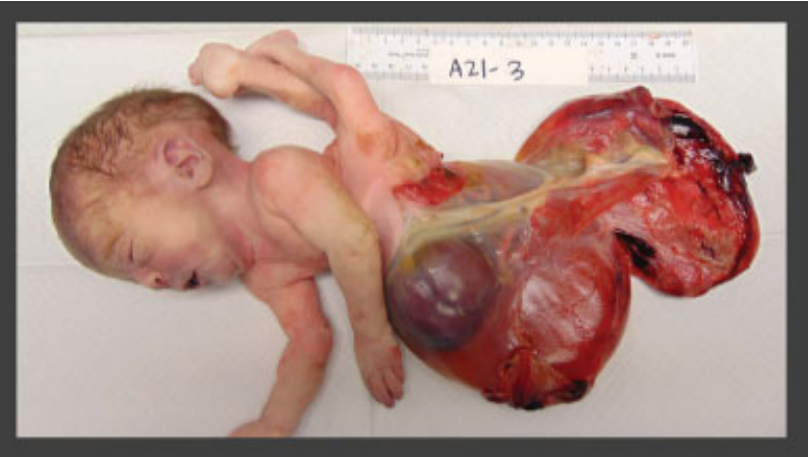

Fig. 1 Severely malformed infant with low-set ears, thoracoabdominoschisis, limb defects with absence of external genitalia and imperforate anus.

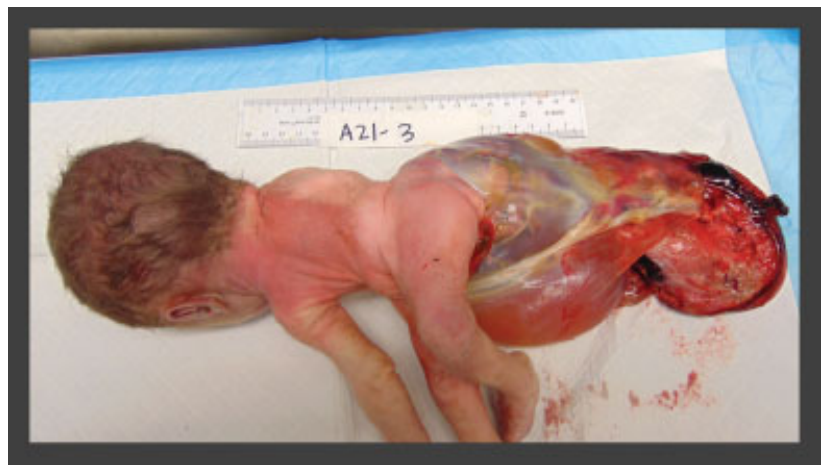

Fig. 3 Dorsal spine with lateral lumbar scoliosis and malrotation of the lower extremities. Note absence of anal opening.

request, neonate was swaddled, allowed to stay with her. The neonate expired about an hour later.

Physical findings on examination of the newborn revealed a growth restricted, significantly malformed infant with thoracoschisis, abdominoschisis, and limb defects, absence of external genitalia, and imperforate anus (-Fig. 1). Infant's

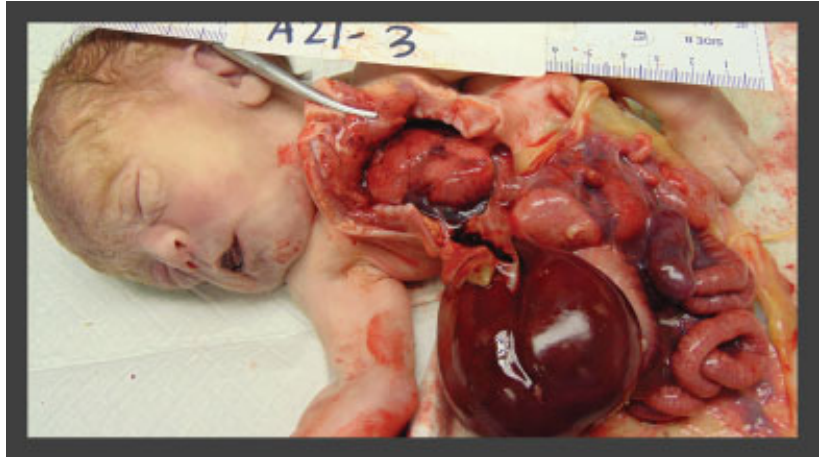

Fig. 2 Autopsy showing abdominal contents with malrotated intestines, hypoplastic lungs.

head and facies were normal except for low-set ears. There was a large anterior abdominal wall defect (abdominoschisis) covered by thin to focal thick translucent membrane (omphalocele) bulging out measuring $11 \times 8 \times 4.6 \mathrm{~cm}$, containing all abdominal viscera and $250 \mathrm{~mL}$ straw tinged fluid ( - Figs. 1 and 2). The spine demonstrated lateral lumbar scoliosis with malrotation of the lower extremities ( $\mathbf{- F i g . ~ 3 ) . ~ B i l a t e r a l ~ c l u b ~}$ foot with left foot displaying fused second and third toes and fused fourth and fifth toes (syndactyly) ( - Figs. 4 and $\mathbf{5}$ ).

\section{Pathology Findings}

At autopsy, the above-mentioned findings were confirmed. Thoracic organs were in their normal anatomic location. Dissection of the heart revealed a patent ductus arteriosus with otherwise normal heart structures. Both lungs were hypoplastic with normal lobations. Right lung weighed $3 \mathrm{~g}$ and the left $2 \mathrm{~g}$, with combined weight of $5 \mathrm{~g}$ (reference range: $30.2 \pm 19 \mathrm{~g}$ ). The lung-to-body weight ratio is 0.0038 (reference $<0.012$, suggestive of pulmonary hypoplasia) (-Fig. 2 ).

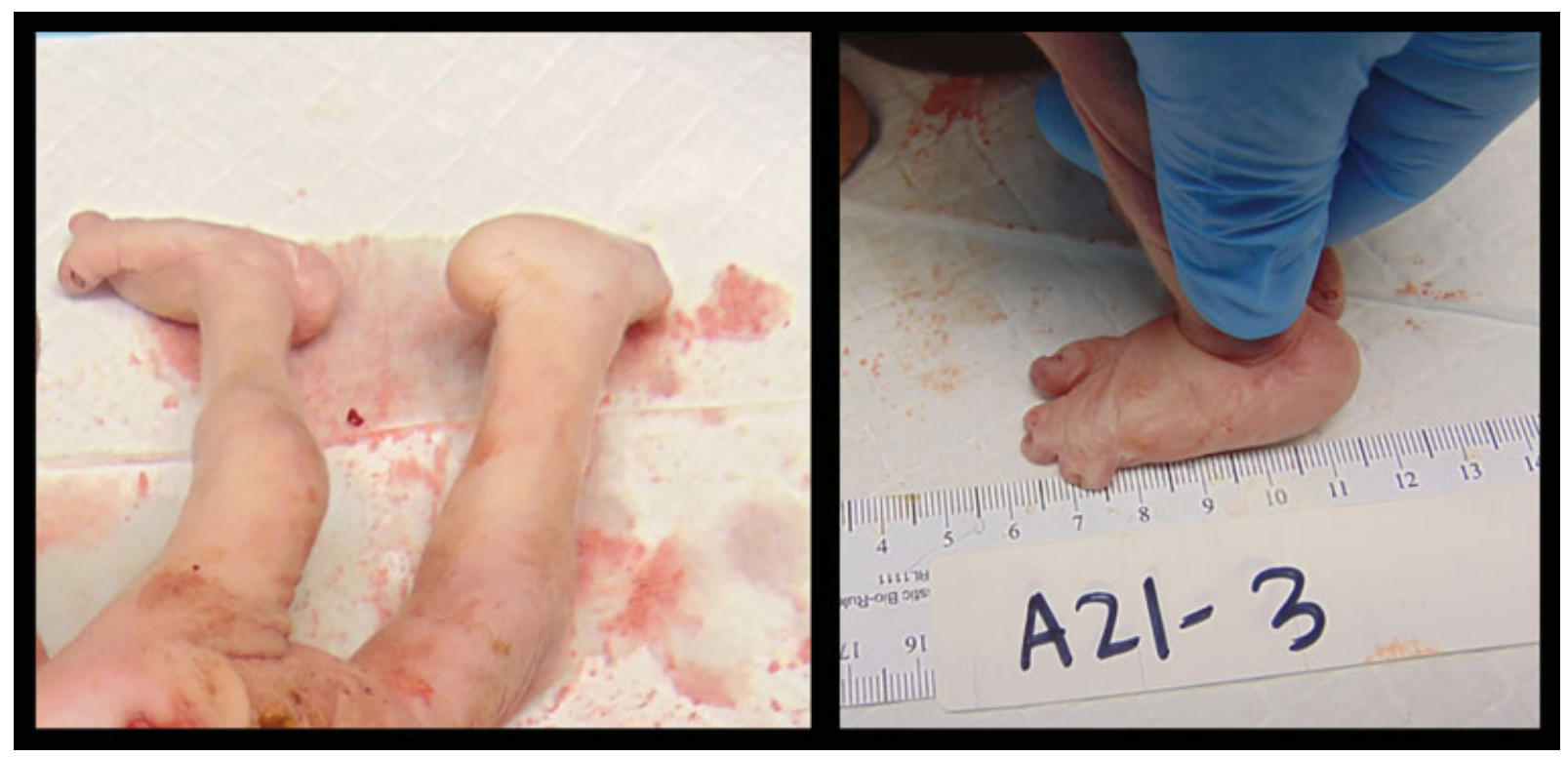

Fig. 4 Bilateral club foot with malformed digits. 


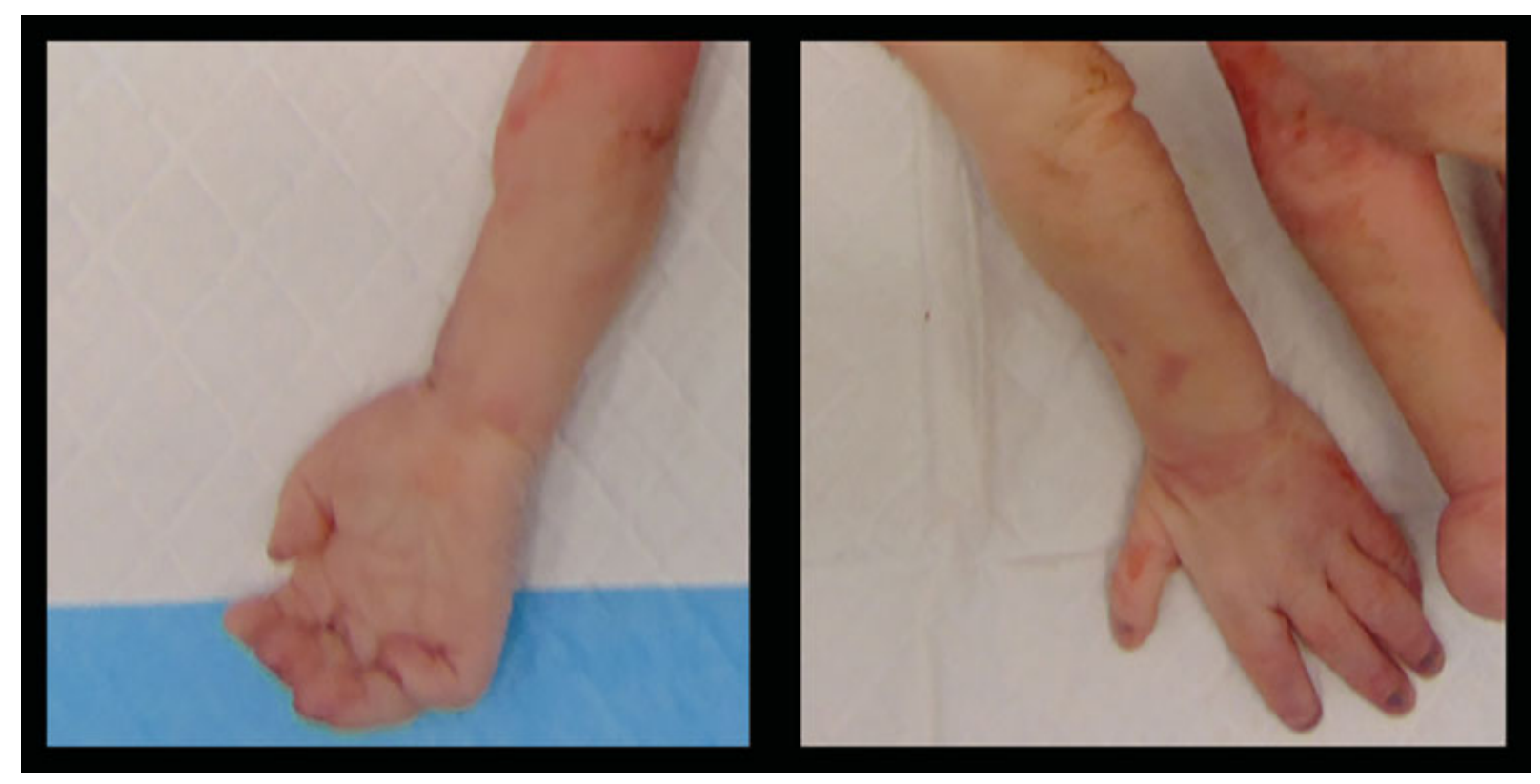

Fig. 5 Syndactyly of fingers.

The thyroid gland appeared normal with no parathyroid glands identified. The esophagus, stomach, pancreas, liver, and small intestine were unremarkable. The colon/large intestine, appendix, and gallbladder were absent (-Fig. 5). Intestines were malrotated, and the diaphragm was intact. The kidneys were symmetrically enlarged $(R>L)$ each weighing $12 \mathrm{~g}$ (reference range: combined weight $15.2 \pm 7.4 \mathrm{~g}$ ). The right ureter was noted to be dilated with a blind thin-walled bladder without an outlet. The thymus and spleen were small. Skeletal examination revealed normal skull, costal ribs with normal costochondral junctions, vertebral bodies, and intervertebral discs. The cranial contents were grossly normal. A single undescended testicle was present with ectopic adrenal tissue, two scrotal tissues in the pelvis.

Microscopic examination of the organs was not contributory as per examining pathologist. Fetal chromosomal analysis demonstrated a normal male karyotype (46, XY) with microarray confirming a normal male $\operatorname{arr}(1-22) \times 2,(X Y) \times 1$. On external examination, the placenta was normal, although small, less than 10th percentile weight with short two-vessel umbilical cord.

\section{Discussion}

Limb-body wall defect is a rare condition with a reported frequency of between 1 per 14,000 and 1 per 31,000 pregnancies in large epidemiologic studies. The LBWC aka body stalk syndrome is characterized by severe congenital malformations, mainly thoracoschisis, abdominoschisis, limb defects, and exencephaly. In our index case, apart from abdominoschisis, an interesting significant finding noted was absent external genitalia, imperforate anus associated with the other classic LBWC anomalies. Most fetuses are aborted, either spontaneously or medical termination with remaining stillborn fetuses. The exact etiology is unknown, and no teratogen has been implicated, and no genetic abnormality has been specifically identified. Reports of familial recurrence of one sibling with LBWC and another with amniotic band sequence (ABS) and another report of two siblings born with LBWC have been reported suggesting the possibility of a genetic origin of the condition. ${ }^{1}$

While some of the diagnostic criteria for LBWC are still being discussed, the most commonly quoted are those originally set forth by Van Allen et al in $1987,{ }^{2}$ who describe the presence of two of the following three malformations: exencephaly/encephalocele and facial clefts; thoraco- and/or abdominoschisis; and limb defects. However, these criteria certainly imply that an infant with encephalocele with facial clefts and limb defects can be considered as having LBWC and are hence disputed because it would be inappropriate to make the diagnosis in the absence of a body wall defect, which appears to be the primary anomaly.

In 1993, Russo et $\mathrm{al}^{3}$ identified two distinct phenotypes of LBWC, one described with craniofacial defects, facial clefts, amniotic adhesions, and amniotic band sequences (ABSs) called placentocranial adhesion phenotype and another without craniofacial defects but with imperforate anus, urogenital abnormalities, lumbosacral meningomyelocele, and kyphoscoliosis called the placentoabdominal adhesion phenotype. Our case resembles the placentoabdominal phenotype. The authors suggest pathogenesis of the first type may be related to an early vascular disruption, while the pathogenesis of the second one is attributable to an intrinsic embryonal maldevelopment. In 1997, Martínez-Frías ${ }^{4}$ suggested that those cases with body wall defect be classified in two main groups: gastroschisis, for cases with an isolated (and usually small) body wall defect, and BWC, for those cases with the body wall defect associated with other malformations, deformations, or disruptions, regardless of their clinical pattern and the possible etiology or pathogenetic 
Table 1 Published cases of LBWC with associated malformations of genitalia

\begin{tabular}{|l|l|l|l|}
\hline $\begin{array}{l}\text { Author } \\
\text { (published year) }\end{array}$ & Title & $\begin{array}{l}\text { Number of cases reported } \\
\text { with defective/absent geni- } \\
\text { talia }\end{array}$ & $\begin{array}{l}\text { Thoracoschisis/abdomi- } \\
\text { noschisis }\end{array}$ \\
\hline Litwin et al (1988) & $\begin{array}{l}\text { Complete absence of external gen- } \\
\text { italia in limb-body wall complex: } \\
\text { two cases }\end{array}$ & 2 & $\begin{array}{l}\text { Both cases had } \\
\text { abdominoschisis }\end{array}$ \\
\hline Colpaert et al (2000) & $\begin{array}{l}\text { Limb-body wall complex: 4 new } \\
\text { cases illustrating the importance of } \\
\text { examining placenta and umbilical } \\
\text { cord }\end{array}$ & $\begin{array}{l}\text { 3-absent external genitalia, } \\
\text { abnormal internal genitalia } \\
1-\text { had normal genitalia }\end{array}$ & $\begin{array}{l}\text { 3-abdominoschisis } \\
1-\text { had both abdominoschisis } \\
\text { and thoracoschisis }\end{array}$ \\
\hline Gajzer et al (2015) & $\begin{array}{l}\text { Possible genetic origin of limb- } \\
\text { body wall complex }\end{array}$ & $\begin{array}{l}\text { 4-absent external genitalia } \\
1-\text { absent internal genitalia }\end{array}$ & $\begin{array}{l}\text { 3-abdominoschisis } \\
1-\text { had both abdominoschisis } \\
\text { and thoracoschisis }\end{array}$ \\
\hline $\begin{array}{l}\text { Baruah and Ray } \\
\text { Choudhury (2013) }\end{array}$ & $\begin{array}{l}\text { Limb-body wall complex with sac- } \\
\text { rococcygeal mass and agenesis of } \\
\text { external genitalia }\end{array}$ & $1-$ absent external genitalia & 1-abdominoschisis \\
\hline
\end{tabular}

mechanism. The spectrum of clinical features described included limb defects present in the vast majority of cases (96\%), absence of a limb is seen in less than a 10th, and upper limb involvement is uncommon. Limb defects include club foot (32\%), oligodactyly (12\%), arthrogryposis/web (12\%), absent limb (9\%), single forearm bone (8\%), single lower leg bone (6\%), pseudo syndactyly (5\%), split hand/foot (5\%), radial/ulnar hypoplasia (4\%), rotational defect $(4 \%)$, and preaxial polydactyly (3\%). Other malformations include absent diaphragm (74\%), abnormal pulmonary lobulations (50\%), trilobulated liver (4\%), polysplenia (4\%), absent gallbladder (29\%), amniotic bands (40\%), and single umbilical artery. Cardiac malformations reported are primitive ventricle (53\%), common atrium (46\%), truncus arteriosus (23\%), atrial septal defect (15\%), membranous ventricular septal defect (8\%), hypoplastic right ventricle $(8 \%)$, and ectopia cordis $(8 \%)$. Gastrointestinal anomalies seen are nonrotated intestine (96\%), intestinal atresia (22\%), anal atresia (17\%), shorted intestines (4\%) and Ladd's bands (4\%). Renal abnormalities reported are unilateral absent kidney (30\%), bilateral absent kidney (4\%), hydronephrosis (17\%), renal dysplasia (9\%), and hypoplastic kidneys (4\%). Urogenital abnormalities seen are abnormal external genitalia (32\%), absent gonad (30\%) and exstrophy of bladder (4\%). The possible theories of etiopathogenesis of LBWC include (1) germ disc defect with early embryonic maldevelopment ${ }^{5}$; primary rupture of the amnion leading to the formation of amniotic bands ${ }^{2}$; vascular disruption ${ }^{2}$; disturbance of the embryonic folding pro$\operatorname{cess}^{6}$; and more recently, potential genetic origin of the complex involving mutation in genes responsible for laterality. ${ }^{7}$ Viscarello et al reported the prenatal detection of two fetuses with LBWC, whose mothers smoked large amounts of cocaine during the first trimester of pregnancy. ${ }^{8}$ Similar findings were reported by Martinez et al in a cocaine abusing mother who presented with severe oligohydramnios caused by premature rupture of membranes, probably related to the cocaine use. They report sonographic findings of an omphalocele, fetal attachment to the placenta, kyphoscoliosis, and absence of a floating umbilical cord. ${ }^{9}$ Similar LBWC with placentoabdominal phenotype is reported by Baruah and Ray Choudhury in an infant born with similar kyphoscoliosis, sacrococcygeal mass, and agenesis of external genitalia. ${ }^{10}$ Prenatal diagnosis is possible by detection of very high maternal serum $\alpha$-fetoprotein and by sonographic visualization of the characteristic defects at the end of the first gestational trimester. Ultrasonographic features include a major abdominal wall defect, severe kyphoscoliosis, a short or absent or rudimentary umbilical cord, and limb abnormalities. The color flow imaging demonstrates single umbilical artery with abnormal fetoplacental attachment. The importance of early antenatal diagnosis in this severe condition with a poor prognosis lies in differentiating it from an isolated gastroschisis or omphalocele, which has a much better prognosis. Early diagnosis can be followed by medical termination of the pregnancy. Postnatal survival for a significant duration is extremely rare, but at least two reported cases, with severe physical handicaps. ${ }^{11,12}$

Although there are several case reports on LBWC, our case highlights complete absence of external genitalia, with findings of a single undescended testicle and two scrotal tissues in the pelvis. To date, there are very few reports of complete absence of the external genitalia associated with LBWC, this is an addition to the existing literature. Or is this a new entity? We further describe the LBWC cases reported to date with associated malformations of genitalia (- Table 1). ${ }^{7,13,14}$

As there is limited understanding regarding etiology, characteristics, possible genetic origin to this entity, reporting this case may give additional information for further research into this entity.

\section{Conclusion}

LBWC is a rare condition with variable presentation. The exact etiology is unclear. Prenatal diagnosis is dependent on sonographic visualization of the characteristic defects discussed earlier. Serum $\alpha$ fetoprotein levels are often elevated. 
This case report is to increase awareness of this entity with its unique presentation of genitourinary and anorectal malformations associated with the classic LBWC defects. The condition carries an extremely poor prognosis as there is no treatment for LBWC and almost all cases reported have been incompatible with life. Many affected pregnancies end in miscarriage or stillbirth. Most infants who survive the prenatal period die shortly after birth. Future pregnancies are however not thought to carry an increased risk of redeveloping the condition.

\section{Lessons for the Clinician}

A systematic approach considering each of the possible differential diagnoses including gastroschisis, omphalocele, pentalogy of Cantrell, amniotic band syndrome (although some characterize LBWC to fall under the spectrum of the amniotic band syndrome), and omphalocele-exstrophy-imperforate anus-spinal defects) ${ }^{15}$ helps in diagnosing this rare presentation. In some cases, autopsy is not performed after the precise prenatal diagnosis (ultrasonography or magnetic resonance imaging). ${ }^{16}$ It is very important to diagnose the complex as early as possible because termination of such a pregnancy is suggested by all authors.

\section{Compliance with Ethical Standards}

Research involving human participants and/or animalsethical approval: All procedures performed in studies involving human participants were in accordance with the ethical standards of the institutional and/or national research committee and with the Declaration of Helsinki 1964 and its later amendments or comparable ethical standards.

\section{Informed Consent}

Informed consent was obtained from all individual participants included in the study.

\section{Conflict of Interest}

The authors deny any conflicts of interest in any terms or by any means during the study. The authors alone are responsible for the content and writing of the article.

\section{References}

1 Luehr B, Lipsett J, Quinlivan JA. Limb-body wall complex: a case series. J Matern Fetal Neonatal Med 2002;12(02):132-137

2 Van Allen MI, Curry C, Gallagher L. Limb body wall complex: I. Pathogenesis. Am J Med Genet 1987;28(03):529-548

3 Russo R, D’Armiento M, Angrisani P, Vecchione R. Limb body wall complex: a critical review and a nosological proposal. Am J Med Genet 1993;47(06):893-900

4 Martínez-Frías ML. Clinical and epidemiological characteristics of infants with body wall complex with and without limb deficiency. Am J Med Genet 1997;73(02):170-175

5 Bamforth JS. Amniotic band sequence: Streeter's hypothesis reexamined. Am J Med Genet 1992;44(03):280-287

6 Hartwig NG, Vermeij-Keers C, De Vries HE, Kagie M, Kragt H. Limb body wall malformation complex: an embryologic etiology? Hum Pathol 1989;20(11):1071-1077

7 Gajzer DC, Hirzel AC, Saigal G, Rojas CP, Rodriguez MM. Possible genetic origin of limb-body wall complex. Fetal Pediatr Pathol 2015;34(04):257-270

8 Viscarello RR, Ferguson DD, Nores J, Hobbins JC. Limb-body wall complex associated with cocaine abuse: further evidence of cocaine's teratogenicity. Obstet Gynecol 1992;80(3 Pt 2)523-526

9 Martinez JM, Fortuny A, Comas C, et al. Body stalk anomaly associated with maternal cocaine abuse. Prenat Diagn 1994;14 (08):669-672

10 Baruah P, Ray Choudhury P. Limb body wall complex with sacrococcygeal mass and agenesis of external genitalia. Case Rep Med 2013;2013:218626

11 Gazolla AC, da Cunha AC, Telles JAB, et al. Limb-body wall defect: experience of a reference service of fetal medicine from Southern Brazil. Birth Defects Res A Clin Mol Teratol 2014;100(10): 739-749

12 Kanamori Y, Hashizume K, Sugiyama M, et al. Long-term survival of a baby with body stalk anomaly: report of a case. Surg Today 2007;37(01):30-33

13 Litwin A, Merlob P, Grunebaum M. Complete absence of external genitalia in limb-body wall complex: two cases. J Med Genet 1988;25(05):340-343

14 Colpaert C, Bogers J, Hertveldt K, Loquet P, Dumon J, Willems P. Limb-body wall complex: 4 new cases illustrating the importance of examining placenta and umbilical cord. Pathol Res Pract 2000; 196(11):783-790

15 Smith NM, Chambers HM, Furness ME, Haan EA. The OEIS complex (omphalocele-exstrophy-imperforate anus-spinal defects): recurrence in sibs. J Med Genet 1992;29(10):730-732

16 Gulczyński J, Świątkowska-Freund M, Paluchowski P, HermannOkoniewska B, Iżycka-Świeszewska E. Limb body wall complex the history of the entity and presentation of our series of cases. Pol J Pathol 2019;70(01):33-41 